\title{
Surface Modifications of Superparamagnetic Iron Oxide Nanoparticles with Polylactic Acid-Polyethylene Glycol Diblock Copolymer and Graphene Oxide for a Protein Delivery Vehicle
}

\author{
Linh Doan, ${ }^{1,2}$ Yang Lu, ${ }^{3}$ Megha Karatela, ${ }^{1}$ Vu Phan, ${ }^{1}$ Clayton Jeffryes, ${ }^{1,4^{*}}$ Tracy Benson ${ }^{1,2^{*}}$ and Evan K. Wujcik ${ }^{1,3^{*}}$
}

As a protein delivery vehicle, superparamagnetic iron oxide nanoparticles (SPION) with an average size of $19.6 \pm 4.8 \mathrm{~nm}$ were coated with polylactic acid (PLA) (5000)-polyethylene glycol (PEG) (10000) diblock copolymer and single layer graphene oxide (GO). Bovine serum albumin was selected as the model protein, and the drug loading capacity of the designed vehicle is $2013 \pm 79 \mathrm{mg}^{-1}$. The drug release result shows that the average percentage of cumulative drug release after 47 days in vitro is $37.7 \% \pm 1.4 \%$.

Keywords: Super paramagnetic iron oxide nanoparticles; Graphene oxide; Diblock co-polymer

Received 18 December 2018, Accepted 24 April 2019

DOI: $10.30919 / \mathrm{es} 8 \mathrm{~d} 510$

\section{Introduction}

Today, even with great advances in cancer treatments such as surgery, radiotherapy, and chemotherapy, cancer is still one of the deadliest threats to human health. ${ }^{1,2}$ Chemotherapy and radiotherapy, which depend heavily on anticancer drugs, can have negative side effects on the cardiovascular, digestive, and respiratory system. ${ }^{3,4}$ Hence, delivering a minimum quantity of total drug to patients, while maximizing delivery to targeted tissues, is of great importance.

SPIONs have many applications in the biomedical industry. For example, iron oxide nanoparticles are used as T2 contrast agents due to their predominant T2-relaxation effects, giving rise to signal reduction on T2-weighted images. ${ }^{5}$ The recently demonstrated use of biovectorized particles for target-specific imaging creates the possibility for MRI molecular probes. ${ }^{7}$ Moreover, SPIONs have superparamagnetism that can be controlled by an external magnetic field, which can enable guided drug delivery to targeted areas in the human body. ${ }^{8}$ By doing so, the dosage of medication can be decreased and the side effects of the medicine can be kept to a minimum. ${ }^{1}$ SPIONs can also be applied to in vitro applications such as genetics research, and other biomedical technologies based on immune magnetic separation of cells, proteins,

${ }^{\prime}$ Dan F. Smith Department of Chemical Engineering, Lamar University, Beaumont, TX, USA

2OPERANDO Spectroscopy Laboratory, Dan F. Smith Department of Chemical Engineering, Lamar University, Beaumont, TX, USA

${ }^{3}$ Materials Engineering And Nanosensor (MEAN) Laboratory, Department of Chemical and Biological Engineering, The University of Alabama, Tuscaloosa, AL, USA

${ }^{4}$ Nanobiomaterials and Bioprocessing (NAB) Laboratory, Dan F. Smith Department of Chemical Engineering, Lamar University, Beaumont, TX, USA

*E-mail: tracy.benson@lamar.edu; cjeffryes@lamar.edu;

Evan.Wujcik@ua.edu deoxyribonucleic acid/ ribonucleic acid (DNA/RNA), bacteria, virus, and other biomolecules. ${ }^{1}$

SPIONs can be produced by the co-precipitation, microemulsion, hydrothermal synthesis, and high temperature decomposition methods. ${ }^{6}$ The co-precipitation method was used in this study which produced primarily magnetite. ${ }^{9}$ In this method, the transformation of magnetite to maghemite can be suppressed. ${ }^{9}$ Another advantage is the rapid and high yield of magnetite. ${ }^{6}$ However, this method has a weak control of the nanoparticle size distribution due to the influence of kinetic factors on nucleation and growth of the crystals, despite the high concentration of nanoparticles per batch.' Another disadvantage is the oxidation and aggregation of SPIONs, ${ }^{6}$ factors that can be minimized by ultrasonication and coating immediately following synthesis.

Hydrophobic SPIONs tend to undergo opsonization and are typically cleared immediately by the mononuclear phagocytic system (MPS). ${ }^{6}$ However, SPIONs can be easily coated with polyethylene glycol (PEG). PEG is soluble in water, and organic solvents such as toluene, and chloroform, and it increases the solubility of other large molecules irrespective of their size. ${ }^{10}$ PEG is widely used as a coating material for nanoparticles due to the following properties: easy excretion through the kidney, low interfacial free energy with water, excluded volume effect, nonimmunogenic, and nonantigenic properties. ${ }^{11}$ PEG coatings suppress platelet adhesion, reducing risk of thrombus formation, tissue damage, and other cytotoxic effect in vitro and in vivo. ${ }^{10}$ PEG does not negatively impact (i.e. protein modification, loss of function or active sites, mutations) active protein or cells even though PEG interacts with some of them directly. ${ }^{10}$ By having a hydrophilic coating on the SPIONs, the in vivo circulation increases because the interaction of the SPIONs with the plasma proteins is avoided, reducing the uptake by the MPS. ${ }^{6}$ Once the SPIONs are coated with PEG, the PEG acts as a good spacer for the attachment of different biomolecules. ${ }^{6}$ Basically, PEG-coated surfaces become hydrophilic and protein rejecting. ${ }^{10}$ In this study, PLA-PEG is selected to coat SPION.

Graphene is a one-atom thick sheet of carbon. ${ }^{12}$ Graphene and graphene oxide (GO) have previously been used for biocompatible 
(materials that do not cause any inflammation or damage to the variety of cells due to non-toxicity $)^{13}$ implantable ${ }^{14}$ applications. GO is oxidized graphene $^{15}$ with surface epoxy and carboxyl groups. ${ }^{12}$ The oxygencontaining function groups in GO give it hydrophilic properties due to enhanced hydrogen bonding. ${ }^{12}$ This hydrophilicity enables biomolecule deposition within GO scaffolds. ${ }^{15}$

PLA-PEG molecules can be attached onto graphene oxide by covalently binding suitable PLA-PEG derivatives on the GO molecules. Another way involves using the functional groups attached to the GO, or attaching amphiphilic PEG copolymers, such as pluronics or poloxamers. ${ }^{15}$ These functional groups are created by strong oxidation and are distributed randomly on the basal planes and the edges of the graphene oxide sheets, oxidizing aromatic rings to generate aliphatic regions $\left(\mathrm{sp}_{3}\right.$ the $\mathrm{sp}_{2}$ hybridized matrix). ${ }^{16}$ In this study, GO is deposited on the outer layer of PLA-PEG, creating a large surface area material with a high concentration of functional groups, enabling high drugloading. ${ }^{16}$

This newly designed drug delivery vehicle will allow loading of high molecular weight drugs that cannot be loaded into other core-shell particles such as SPIONs-mesoporous silica. This drug delivery vehicle also has the potential to load two different types of drugs, is easy to synthesize, and is low-cost.

\section{Experimental Section}

Materials:

Iron (III) chloride hexahydrate, iron (II) chloride tetrahydrate, ammonium hydroxide solution $\left(28 \mathrm{wt} \% \mathrm{NH}_{3}\right.$ in $\left.\mathrm{H}_{2} \mathrm{O}\right)$, and tetrahydrofuran were purchased from Sigma Aldrich. Hydrochloric acid was purchased from Fisher Scientific. Single layer graphene oxide was purchased from Cheap Tube Inc. PEG(10000)-b-PLA(5000) diblock polymer was purchased from Polymersciences. All materials were used as received.

\section{Synthesis of SPIONs:}

SPIONs were synthesized by the co-precipitation method previously described. ${ }^{17}$ First, $500 \mathrm{ml}$ of $0.7 \mathrm{M} \mathrm{NH}_{4} \mathrm{OH}$ was prepared and poured into a two-necked round bottom flask and $\mathrm{N}_{2}$ was bubbled through the solution while stirring. Next, $10.81 \mathrm{~g}$ of $\mathrm{FeCl}_{3} \cdot 6 \mathrm{H}_{2} \mathrm{O}$ was dissolved in $40 \mathrm{ml}$ of DI water and $3.97 \mathrm{~g}$ of $\mathrm{FeCl}_{2} \cdot 4 \mathrm{H}_{2} \mathrm{O}$ was dissolved in $10 \mathrm{ml} 2$ $\mathrm{M} \mathrm{HCl}$. The two iron solutions were then mixed together and the entire $50 \mathrm{ml}$ was added drop-wise to the flask containing $\mathrm{NH}_{4} \mathrm{OH}$ solution. Stirring was reduced when the mixture turned black. The reaction continued for 30 minutes in an $\mathrm{N}_{2}$ atmosphere. The particles were collected at the bottom of the flask using a neodymium magnet and the supernatant was removed and replaced with DI water.

Surface Modification of SPION with PLA-PEG:

This study used emulsion polymerization to coat PLA-PEG on SPION particles. $108 \mathrm{mg}$ of PLA-PEG was mixed with 6-30 mg of SPION, 20 $\mathrm{ml}$ of THF, and $15 \mathrm{ml} \mathrm{DI}$ water. Then, the mixture was sonicated for 2 $\mathrm{h}$, stirred, centrifuged at $3000 \mathrm{rpm}$ for 5 minutes, and heated at $40{ }^{\circ} \mathrm{C}$ until the THF was evaporated. After drying, the total volume was adjusted to $15 \mathrm{ml}$ with DI water. The mixture was then centrifuged and the supernatant was decanted. The product of PLA-PEG coated SPION was kept for further modifications.

Preparation of SPION/PLA-PEG/GO:

Based on the method of Angelopoulou et al. (2015), $300 \mathrm{mg}$ of Graphene Oxide (GO) was mixed with $1500 \mathrm{ml}$ DI water, which gave a concentration of $0.2 \mathrm{mg} \mathrm{ml}^{-1}$, was sonicated for $2 \mathrm{~h}$. Then, $272.5 \mathrm{ml}$ of GO-DI was mixed with SPION/PLA-PEG, which was made in the previous step. This gave the ratio of 50/50 wt $\%$ of GO/PLA-PEG. The GO/PLA-PEG ratio, the molecular weight of the PLA-PEG is based on Angelopoulou et al. study. ${ }^{16}$ The mixture was then bath sonicated for $2 \mathrm{~h}$. Then, the mixture was centrifuged at $1116 \times g$ for $5 \mathrm{~min}$. The supernatant of the mixture was then bath sonicated for $1 \mathrm{~h}$.

Loading of the delivery vehicle:

In this study, all of the experiments were performed in triplicate, and all of the error bars (calculated using standard deviation) are shown in the figures. Error bars shown as one standard deviation, except where otherwise stated.

The SPION/PLA-PEG/GO solution was then dried completely at $80{ }^{\circ} \mathrm{C}$. The weight of SPION/PLA-PEG/GO was measured. Then, the product was divided into three equal aliquots. Next, $1 \mathrm{~g}$ of bovine serum albumin (BSA) was dissolved in $10 \mathrm{ml}$ DI water and $3 \mathrm{ml}$ of stock BSA solution was mixed with $27 \mathrm{ml}$ DI water, which gave a concentration of $10 \mathrm{mg} \mathrm{BSA} \mathrm{ml}{ }^{-1}$. In order to remove the impurities, the mixture was then centrifuged at $500 \mathrm{rpm}$ for 5-10 minutes. The supernatant was removed and equally divided into three vials. The volume of BSA in each vial was measured then mixed with 1 vial of dried SPION/PLA$\mathrm{PEG} / \mathrm{GO} .^{18}$ After extraction, SPION/PLA-PEG/GO was recovered from the suspension using a Neodymium magnet. This extraction process recovered BSA loaded SPION/PLA-PEG/GO nanoparticles, and BSA non-loaded SPION/PLA-PEG/GO nanoparticles. $1 \mathrm{ml}$ of the supernatant was sampled, and the absorbance measured using spectrophotometry at $280 \mathrm{~nm}, 278 \mathrm{~nm}$, and $260 \mathrm{~nm}$ every 10 minutes.

The loading amount $\left(\mathrm{Q}, \mathrm{mg} \mathrm{BSA}\left(\mathrm{g} \mathrm{Fe}_{3} \mathrm{O}_{4} / \mathrm{PLA}-\mathrm{PEG} / \mathrm{GO}\right)^{-1}\right)$ was calculated by following equation ${ }^{18}$ :

$$
Q=\frac{\left(C_{0}-C\right) V}{m}
$$

where $C_{0}$ and $\mathrm{C}$ are the initial concentration and concentration at time, $t$ (min), of BSA in solution ( $\left.\mathrm{mg} \mathrm{BSA} \mathrm{ml}^{-1}\right), \mathrm{V}$ is the reaction volume ( $\mathrm{ml}$ ), and $\mathrm{m}$ is the mass of $\mathrm{Fe}_{3} \mathrm{O}_{4} / \mathrm{PLA}-\mathrm{PEG} / \mathrm{GO}(\mathrm{g})$. The $C_{0}$, $\mathrm{m}$, and $\mathrm{V}$ in this study are $10 \mathrm{mg} \mathrm{ml}^{-1}, 0.059 \mathrm{~g}$, and $10 \mathrm{ml}$, respectively.

The concentration of BSA in the solution can be roughly estimated by the following equation:

$$
C=1.55 \times A_{280}-0.76 \times A_{260}
$$

where $\mathrm{A}_{280}$ and $\mathrm{A}_{260}$ are the spectrophotometric absorbances at $280 \mathrm{~nm}$ and $260 \mathrm{~nm}$, respectively.

The drug loading capacity ( $\% \mathrm{DL})$ was calculated by the following equation: ${ }^{19}$

$\% D L=\frac{\text { Weight of BSA absorped on to the nanoparticles }(\mathrm{mg})}{\text { Weight of nanoparticles }(\mathrm{mg})} \times 100$

The entrapment efficiency $(\% \mathrm{EE})$ was calculated by the following equation: ${ }^{19}$

$\% E E=100 \times \frac{\text { Weight of BSA absorped on to the nanoparticles }(\mathrm{mg})}{\text { Weight of nanoparticles }(\mathrm{mg})}$

$B S A$ release the delivery vehicle:

Each of the magnet-collected BSA-loaded SPION/PLA-PEG/GO samples was mixed with $11 \mathrm{ml}$ of $0.002 \mathrm{M}$ Phosphate Buffer Saline (PBS) in a $15 \mathrm{ml}$ centrifuge tube. Then, the centrifuge tube was incubated in a water bath at $37{ }^{\circ} \mathrm{C}$ and agitated for 10 minutes every $12 \mathrm{~h}$. Every 24 hours, after agitation, the centrifuge tube was centrifuged at $400 \times \mathrm{g}$ for 18 minutes. Then, $4 \mathrm{ml}$ of solution was removed from the centrifuge 
tube and placed in a vial. Then, $4 \mathrm{ml}$ of pure PBS was put in the centrifuge tube to replace the sampled volume. After 34 days, all of the samples were analyzed by UV-vis spectrophotometry at $280 \mathrm{~nm}$ and $260 \mathrm{~nm}$.

The amount of BSA released was calculated using the following equations:

Mass of the BSA in solution:

$$
m_{t, i}=C_{i} \times V_{t}
$$

where $m_{t i}, \mathrm{C}_{\mathrm{i}}$, and $V_{t}$ are the total mass of the BSA in solution at the time of sampling aliquot $i(\mathrm{mg})$, the concentration of BSA in the sampled aliquot $i\left(\mathrm{mg} \mathrm{ml}^{-1}\right)$ and total volume of the solution in the tube $(\mathrm{ml})$, respectively. In this study, $V_{t}=11 \mathrm{ml}$ and the volume aliquot removed for spectrophotometry was $V_{s}=4 \mathrm{ml}$.

The mass of the BSA in the liquid phase in the tube after sampling, $m_{t i+}$, was calculated by:

$$
m_{t, i+}=C_{i} \times\left(V_{t}-V_{s}\right)=m_{t, i}-C_{i} V_{s}
$$

The mass released between removing samples $i$ and $i+1$ was therefore:

$$
m_{d, i}=m_{t, i+1}-m_{t, i+}+C_{i} V_{s}
$$

where $m_{d i}$ is the amount of BSA released during day $i$.

Cumulative drug release is therefore:

$$
\mathrm{Cum}_{n}=\sum_{i=0}^{i=n} m_{d, i}
$$

where $\mathrm{Cum}_{n}$ is the total BSA released (mg) between $t=0$ and day $n$.

The percentage cumulative drug release was calculated by:

$$
\operatorname{PCDRR}_{n}=\frac{\mathrm{Cum}_{n}}{M_{D L}} \times 100
$$

where $P C D R R_{n}$ and $m_{D L}$ are the percentage cumulative drug release (\%) on day $n$ and mass of BSA loaded on the NPs (mg), respectively. In this study, $m_{D L}=110 \mathrm{mg}$.

Scanning Electron Microscope (SEM) measurements:

The morphology of the nanoparticles was characterized with an SEM (JEOL 6500). The operating conditions were: accelerating voltage $5 \mathrm{kV}$, and probe current $20 \mathrm{pA}$. The dried samples were placed on the aluminum stub. ImageJ software was used to calculate the SPIONs diameter distribution from the SEM images. ${ }^{20}$

Fourier Transform Infrared Spectroscopy (FTIR) analysis:

All of the samples were dried, ground, and pressed in $\mathrm{KBr}$ disks before analyzed by a Tensor 27 FTIR spectrometer coupled with a Hyperion 1000 ATR microscope accessory, which were bought from Bruker Optics, Inc.

\section{Results and Discussion}

The SEM and FTIR confirmed the bonding of SPION with PLA-PEG and GO. Moreover, the SEM images clearly show adsorption of BSA to the surface of the SPIONs and FTIR confirms bonding of PLA-PEG and GO to the SPIONs. Taken together, these results imply the successful construction of the SPION/PLA-PEG/GO material with considerable surface loading of BSA.

\subsection{Characterization of the Delivery Vehicle}

SEM and FTIR were used to observe and confirm the bonding of protein to SPION/PLA-PEG/GO on the delivery vehicle.

\subsubsection{SEM Measurements}

SEM images of the SPION materials are presented in Fig. 1. As seen in Fig. 1a, SPION is agglomerated after synthesis. In this study, agglomeration can be avoided by using an ultra-sonic bath.

As seen in Fig. 1b, the SPION particles are much smaller compared to the PLA-PEG polymer. However, at $10 \mu \mathrm{m}$, Fig. 1b shows clearly

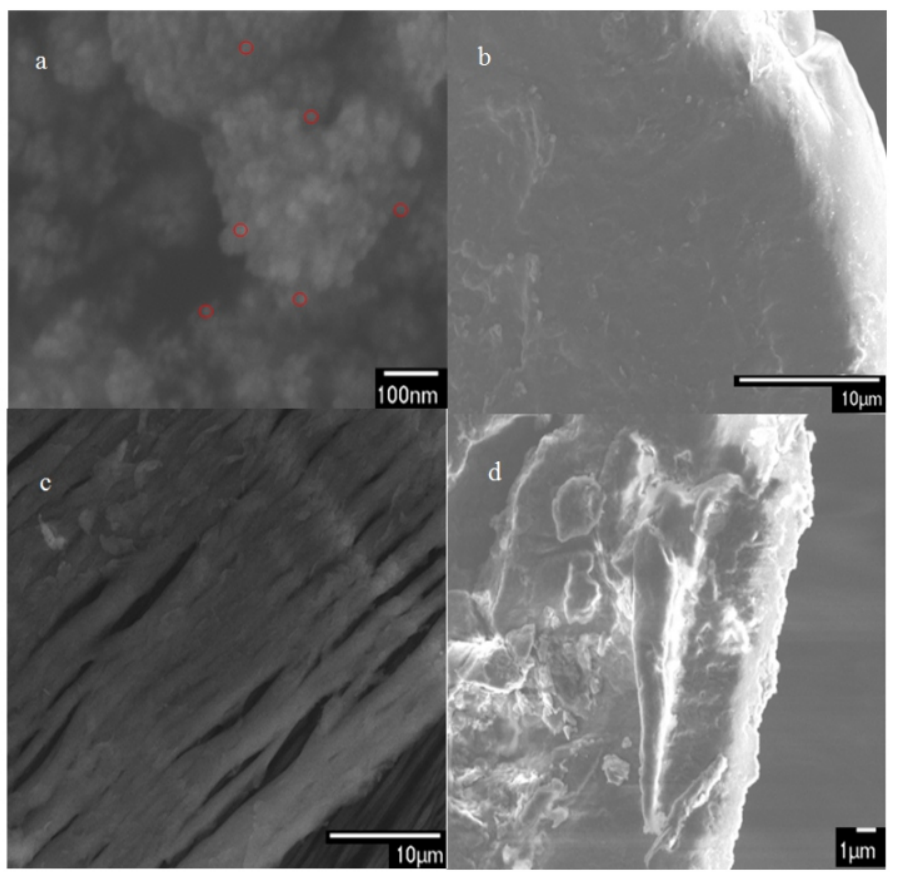

Fig. 1 SEM images a) SPION, b) SPION coated with PLA-PEG, c) SPION coated with PLA-PEG and GO, d) SPION coated with PLA-PEG with BSA attached to GO. 
SPION particles were attached to the polymer, which later was supported and confirmed by FTIR (vide infra).

As seen in Fig. 1c the SPION particle was still attached to the PLA-PEG. However, the SEM can't take an image which shows the GO outside of the PLA-PEG due to the reaction between electron beam and the protein delivery vehicle.

Similar to Fig. 1c, the electron beam reacts with the protein delivery vehicle, GO was not shown in Fig. 1d. However, the reaction rate of electron beam and the protein delivery vehicle was slowed down.

The SPION particle size distribution is presented in Fig. 2. Most particles have a diameter ranging from 15 to $25 \mathrm{~nm}$ with an average diameter of $20 \pm 5 \mathrm{~nm}(1 \sigma)$.

\subsubsection{FTIR}

The FTIR spectra of the SPION, diblock copolymer, and vehicle are shown in Fig. 3. FTIR is an effective instrument to quantitate the structure on the functional groups in nanoparticles. This measurement was used to determine the functional groups, which in turn confirms the final structure of the drug delivery vehicle.

As seen in Fig. 3, for SPION/PLA-PEG/GO ratio 1:2 (wt/wt) spectra, the peak at $1751 \mathrm{~cm}^{-1}$ shows the stretching frequencies for $\mathrm{C}=\mathrm{O}$ which matches GO and PLA-PEG spectra. Moreover, all of the peaks from $500 \mathrm{~cm}^{-1}$ to $2500 \mathrm{~cm}^{-1}$ match the PEG-PLA spectra. At $3410 \mathrm{~cm}^{-1}$, SPION/PLA-PEG/GO ratio 1:2 (w/w) peak matches the peak of GO at $3426 \mathrm{~cm}^{-1}$ and the peak of SPION at $3418 \mathrm{~cm}^{-1}$. The peak at $1751 \mathrm{~cm}^{-1}$, $632 \mathrm{~cm}^{-1}$ in SPION/PLA-PEG/GO matches the peak at $1732 \mathrm{~cm}^{-1}, 632$ $\mathrm{cm}^{-1}$ in GO and SPION respectively. The peak at $1624 \mathrm{~cm}^{-1}$ in GO matches SPION/PLA-PEG/GO spectra as depicted in Fig. 3. These spectra suggest that the drug delivery vehicle has been successfully assembled as described.

\subsubsection{Loading of the Delivery Vehicle}

This study loaded high molecular weight proteins by depositing them on the surface of the GO layer of the SPION/PLA-PEG/GO delivery vehicle. Hence, the larger the protein size, the better for the study. Currently, the two main proteins that many studies are focusing on are BSA and bovine hemoglobin (BhB). The average dimension of a single hemoglobin and serum albumin are $6 \times 5 \times 5 \mathrm{~nm}$, and $7.5 \times 6.5 \times 4.0$ $\mathrm{nm}$, respectively. ${ }^{28}$ Because BSA has larger dimensions than hemoglobin, the BSA protein was chosen as the model protein to test the drug loading capacity.

The amount of BSA adsorbed on the surface of SPION/PLA$\mathrm{PEG} / \mathrm{GO}$ is presented in Table 2. The mass of BSA adsorbed onto $\mathrm{Fe}_{3} \mathrm{O}_{4} / \mathrm{PLA}-\mathrm{PEG} / \mathrm{GO}$ first increases quickly due to the initial availability

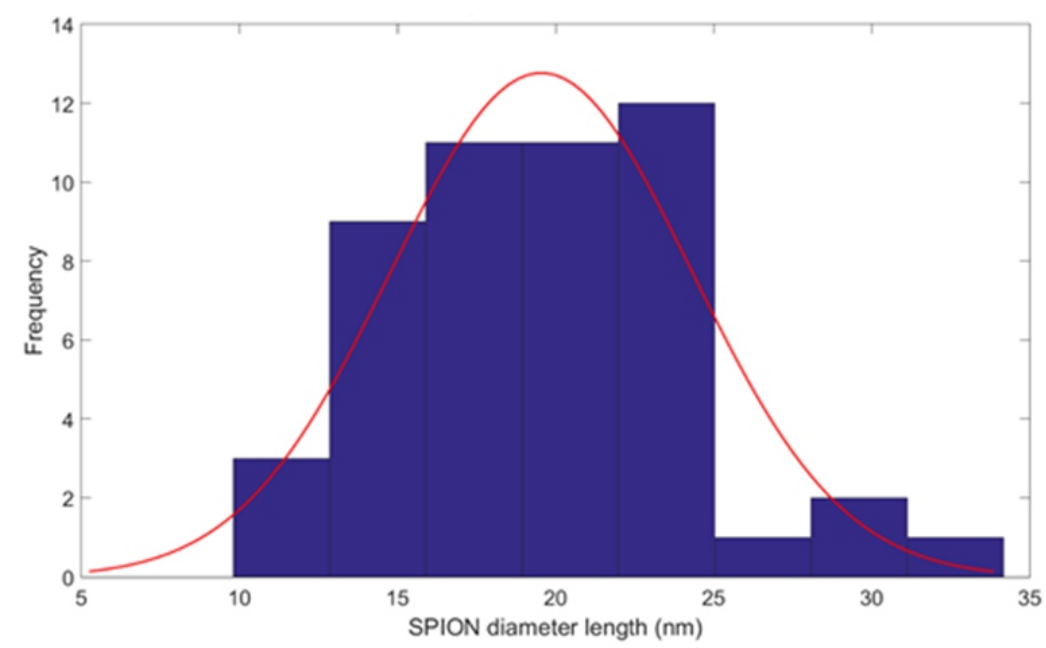

Fig. 2 The normal distribution of SPION diameter as determined using SEM software.

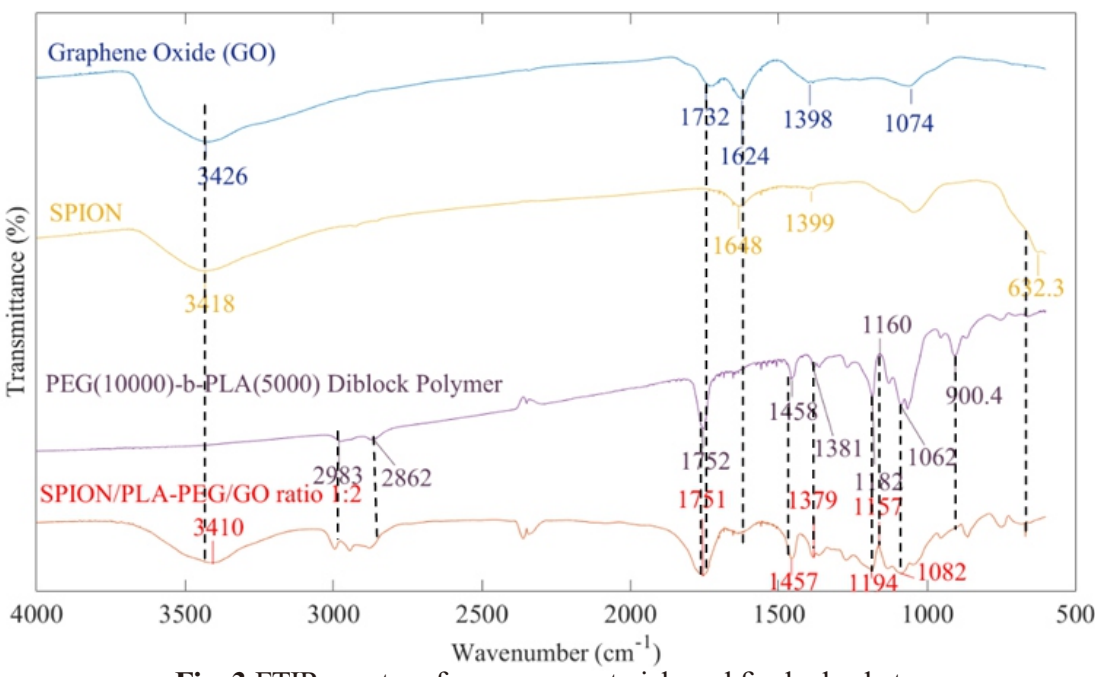

Fig. 3 FTIR spectra of precursor materials and final adsorbate. 
Table 1 FTIR spectra analysis.

\begin{tabular}{llll}
\hline Spectra & Wavelength $\left(\mathrm{cm}^{-1}\right)$ & Group & Ref. \\
\hline PLA-PEG & 1752 & $\mathrm{C}=\mathrm{O}$ & 21 \\
& 2983 & $-\mathrm{CH}_{3}$ asymmetric stretch & 21 \\
& 2862 & $-\mathrm{CH}_{3}$ symmetric stretch & 21 \\
& 1062 & $\mathrm{C}-\mathrm{O}$ & 21 \\
& 1458 & $-\mathrm{CH}_{3}$ asymmetric bend & 21 \\
& 1381 & $-\mathrm{CH}_{3}$ symmetric bend & 21 \\
$\mathrm{GO}$ & 3426 & $-\mathrm{OH}$ & \\
& 1732 & $\mathrm{C}=\mathrm{O}$ & $18,22,23,24$ \\
& 1624 & $\mathrm{C}=\mathrm{C}$ & $18,22,24$ \\
SPION & 3418 and 1648 & $\mathrm{Bending}$ vibration of absorbed & 25 \\
& & water and surface hydroxyl and & \\
& & $\mathrm{O}-\mathrm{H}$ stretching mode & 25 \\
& $900-1000$ & Presence of nitrate group & 26 \\
& 632.3 & Fe-O bonds in the crystalline latticeof $\mathrm{Fe}_{3} \mathrm{O}_{4}$ & 26,27 \\
\hline
\end{tabular}

Table 2 Drug loading capacity, percentage, and entrapment efficiency.

\begin{tabular}{lll}
\hline Average Q $\left(\mathrm{mg} \mathrm{g}^{-1}\right)$ & Drug Loading (\%) & Entrapment Efficiency (\%) \\
\hline $2013 \pm 79(1 \sigma)$ & $185.8 \pm 0.0(1 \sigma)$ & $99.7 \pm 0.0(1 \sigma)$ \\
\hline
\end{tabular}

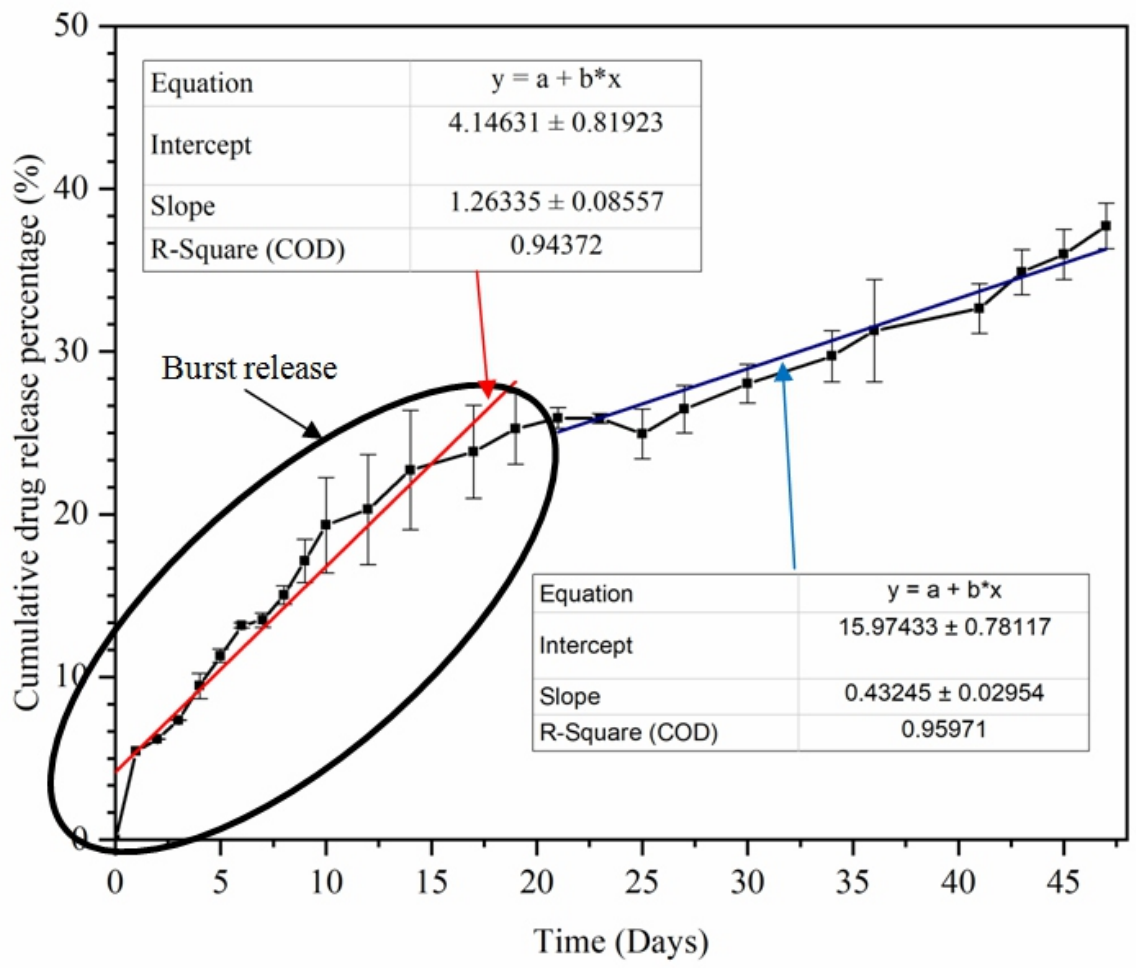

Fig. $4 P C D R R_{n}$ versus time $(1 \sigma)$. 
of activated graphene oxide sites due to the high concentration of BSA. After 1 minute, the BSA has occupied most of the activated sites of the $\mathrm{GO}$ and has reached the equilibrium state. The average $\mathrm{Q}$ at equilibrium is $2013 \pm 79\left(\mathrm{mg} \mathrm{g}^{-1}\right)(1 \sigma)$.

As seen in Table 2, the average drug loading percentage is $185.8 \pm$ $0.0 \%(1 \sigma)$. Our model drug compound, BSA, was adsorbed onto the surface of the nanoparticles very quickly and reached the equilibrium state after $1 \mathrm{~min}$

As seen in Table 2, the entrapment efficiency percentage reached $99.7 \pm 0.0 \%(1 \sigma)$ by $\mathrm{t}=5 \mathrm{~min}$. Based on the results from Table 2 , for 1 $\mathrm{mg}$ of SPION/PLA-PEG/GO, approximately $1.85 \mathrm{mg}$ of BSA adsorbed onto the surface of the nanoparticles.

This study shows that the SPION/PLA-PEG/GO can be used as potential drug delivery vehicle for large molecules such as BSA (66 $\mathrm{kDa}){ }^{29}$ This vehicle can adsorb a large quantity of drugs and has a very high entrapment efficiency in a short period of time. Comparing the drug loading capacity to previous study, ${ }^{30}$ BSA adsorption capacity on GO is similar (200.01 $\mathrm{mg} \mathrm{g}^{-1}$ ). This adsorption can be ascribed to a chemisorption mechanism. ${ }^{30}$ Moreover, because of the abundance of carboxylic acid groups, $\pi-\pi^{*}$ stacking interactions, hydrophilic characteristic, and different types of forces such as van der Waals interactions, electrostatic forces, hydrophobic forces, and hydrogen bonds, large amount of BSA can be adsorbed on $\mathrm{GO}^{30}$

\subsubsection{Release of the Delivery Vehicle}

This study analyzed the release of BSA from the loaded delivery vehicle. Based on the absorbance from the UV-vis spectrophotometer, the cumulative drug release percentage is presented in Fig. 4.

The cumulative drug release percentage $\left(P C D R R_{n}\right)$ is increasing steadily. Fig. 4 also shows that the standard deviation is small, which means that the releasing experiment is accurate and repeatable. By the end of day 47 , the $P C D R R_{n}$ is $37.7 \pm 1.4 \%(1 \sigma)$. From day 0 to day 20 , the vehicle exhibits the burst release phenomenon. ${ }^{31}$ The $\mathrm{PCDRR}_{\mathrm{n}}$ at the end of the burst release was $25.9 \pm 0.6 \%(1 \sigma)$. The initial burst release is possibly caused by the interaction between BSA and the graphene oxide such as a strong - stacking between BSA and SPION/PLAPEG/GO ${ }^{31,32}$ According to X. Huang et al., burst release has not shown to understand the mechanisms of burst release in monolithic polymeric systems. ${ }^{31}$ Another cause for the burst release is the result of a high drug concentration between the bulk solution and the BSA molecules which is attached on the GO surface. ${ }^{33}$ Hence, X. Huang et al. discussed that burst release of proteins is often caused by the surface adhesion, and desorption, and the thermodynamic imbalances because the solubility of drugs and their partition coefficients affect the driving forces for release. ${ }^{31}$ Another cause for the initial burst release of BSA during the initial release process is the quick swollen rate of the PLA-PEG, and the weak interaction between PLA-PEG matrix and BSA. ${ }^{34}$ The burst release can be avoided by cross-linking the polymer on the GO/SPION surface. ${ }^{35}$ Delivery vehicles that undergo burst release typically require more frequent dosing. ${ }^{31}$ However, after 45 days this delivery vehicle only released $37.7 \pm 1.4 \%(1 \sigma)$ of the BSA. Therefore, this delivery vehicle shows the potential for long-term release without requiring frequent dosing. This drug release model looks very similar to the release of BSA from poly (DL-lactide/glycolide, 50:50, Dupont). Moreover, the BSA burst release phenomena can also be seen similarly in Sershen et al. study. ${ }^{37}$ After the burst effect, the delivery vehicle sustained a near constant release rate $\left(\mathrm{R}^{2}=0.96\right)$. After day 47 , polymer residue was suspended inside the $15 \mathrm{ml}$ PBS centrifuge tube. This phenomenon suggests the degradation of the polymer. Hence, the drug release experiment was stopped after 47 days because the solution inside the centrifuge tube contained degraded polymer, and BSA. This would affect the readings of the BSA absorbance using by spectrophotometry. Further study will be required to eliminate the burst release effect.

As seen in Table 3, SPION/PLA-PEG/GO drug delivery vehicle has the highest entrapment efficiency, and one of the lowest cumulative drug release percentage.

\section{Conclusions}

In summary, this study has developed an easily synthesized, low-cost, and effective protein delivery carrier using SPION/PLA-PEG/GO. By using SEM, UV-Vis Spectroscopy, and FTIR, the size of the particle, the drug loading capacity, and the confirmation of the bonding of SPION, PLA-PEG, and GO were determined. This carrier has the size of $20 \pm 5 \mathrm{~nm}(1 \sigma)$ and a drug loading capacity of $2013 \pm 79 \mathrm{mg} \mathrm{g}^{-1}(1 \sigma)$. This study also shows that the drug loading percentage and entrapment efficiency are $185.8 \pm 0.0 \%(1 \sigma)$, and $99.3 \pm 0.2 \%(1 \sigma)$, respectively. This study also shows that the average percentage cumulative drug

Table 3 Comparison table between different types of drug delivery vehicle.

\begin{tabular}{|c|c|c|c|}
\hline Drug Delivery Vehicle & Entrapment Efficiency (\%) & Cumulative drug release percentage (\%) & Reference \\
\hline SPION/PLA-PEG/GO & $99.7 \pm 0.0(1 \sigma)$ & $37.7 \pm 1.4($ after 47 days $)(1 \sigma)$ & This study \\
\hline PLGA & $63.8 \pm 1.4$ & 49.8 (after 7 days) & 38 \\
\hline PEG-PLGA & $48.6 \pm 1.1$ & 71.4 (after 7 days) & 38 \\
\hline Layer-by-layer alginate, chitosan (5 layers) & $\sim 80$ & $\sim 30$ (after 30 days) & 39 \\
\hline Dextran hydrogels & - & 60 (after $7 \sqrt{\text { hours }})$ & 40 \\
\hline $\begin{array}{l}\text { PEG-g-chitosan hydrogels crosslinked with genipin with } \\
\text { BSA concentrations } 1000 \mu \mathrm{g} / \mathrm{ml}\end{array}$ & - & $\sim 80$ (after 40 days) & 41 \\
\hline Alginate and montmorillonite composite beads $2 \% \mathrm{w} / \mathrm{v}$ & 78 & $\sim 40$ (after 10 hours) & 42 \\
\hline
\end{tabular}


release after 47 days in vitro is $37.7 \pm 1.4 \%(1 \sigma)$, with the burst release effect in the first 20 days. This study can be researched further by testing the drug release test in in vivo.

\section{Conflict of interest}

There are no conflicts to declare.

\section{Acknowledgements}

Financial supports from the Lamar University Dan F. Smith Department of Chemical Engineering and College of Engineering are gratefully acknowledged.

\section{References}

1. E. Senkus and J. Jassem, Cancer. Treat. Rev., 2011, 37, 300 .

2. W. Kucharska, M. Negrusz-Kawecka and M. Gromkowska, Adv. Clin. Exp. Med, 2012, 21, 281.

3. S. Jin and K. Ye, Recent. Pat. Anticancer Drug. Discov., 2013, 8, 143.

4. G. Minotti, A. Saponiero, S. Licata, P. Menna, A. M. Calafiore, G. Teodori and L. Gianni, Clin. Cancer. Res., 2001, 7, 1511.

5. Z. Zhao, Z. Zhou, J. Bao, Z. Wang, J. Hu, X. Chi, K. Ni, R. Wang, X. Chen, Z. Chen and J. Gao, Nat. Commun., 2013, 4, 2266.

6. M. Muthiah, I. K. Park and C. S. Cho, Biotechnol. Adv., 2013, 31, 1224.

7. R. Qiao, C. Yang and M. Gao, J. Mater. Chem., 2009, 19, 6274.

8. T. Neuberger, B. Schöpf, H. Hofmann, M. Hofmann and B. von Rechenberg, J. Magn. Magn. Mater., 2005, 293, 483

9. A. Marinin, Synthesis and characterization of superparamagnetic iron oxide nanoparticles coated with silica. Master Thesis, Royal Institute of Technology: Stockholm, Stockholm, 2012.

10. N. A. Alcantar, E. S. Aydil and J. N. Israelachvili, J. Biomed.Mater. Res., 2000, 51, 343.

11. A. K. Gupta and S. Wells, IEEE T. Nanobiosci., 2004, 3, 66.

12. P. Gao, M. Liu, J. Tian, F. Deng, K. Wang, D. Xu, L. Liu, X. Zhang and Y. Wei, Appl. Surf. Sci., 2016, 378, 22.

13. Y. Zhang, T.R. Nayak, H. Hong and W. Cai, Nanoscale, 2012, 3833-3842.

14. E. K. Wujcik and C. N. Monty, Wires. Nanomed. Obi., 2013, 5, 233-249.

15. D. W. Boukhvalov, Phys. Chem. Chem. Phys.s, 2010, 12, 15367.

16. A. Angelopoulou, E. Voulgari, E. K. Diamanti, D. Gournis and K. Avgoustakis, Eur. J. Pharm. Biopharm., 2015, 93, 18-26.

17. I. J. Bruce, J. Taylor, M. Todd, M. J. Davies, E. Borioni, C. Sangregorio and T. Sen, J. Magn. Magn. Mater, 2004, 284, 145-160.
18. Y. Huang, Y. Wang, Q. Pan, Y. Wang, X. Ding, K. Xu, N. Li and Q. Wen, Anal. Chim. Acta, 2015, 877, 90.

19. S. Papadimmitriou and D. Bikiaris, J. Control. Release, 2009, 138, 177-184.

20. S. J. Kiprono, M. W. Ullah and G. Yang, Appl.Microb. Cell Phys., 2017, 102, 933-944.

21. B. Chieng, N. Ibrahim and W. Yunus, M. Hussein, Polymers, 2013, 6, 93.

22. M. Fu, Q. Jiao, Y. Zhao and H. Li, J. Mater. Chem. A, 2014, $2,735$.

23. P. Lian, X. Zhu, S. Liang, Z. Li, W. Yang and H. Wang, Electrochim. Acta 2010, 55, 3909.

24]. S. Gurunathan, J. W. Han, J. H. Park, E. S. Kim, Y. J. Choi, D. N. Kwon and J. H. Kim, Int. J. Nanomed., 2015, 10, 4203-4222.

25. S.W. Hwang, A. Umar, G. N. Dar, S.H. Kim and R. I. Badran, Sens. Lett., 2014, 12, 1-5.

26. J. Lopez, F. González, F. Bonilla, G. Zambrano and M. Gómez, Rev Latinoam. Metal. Mater, 2010, 30, 60-66.

27. M. D. Adhikari, S. Mukherjee, J. Saikia, G. Das and A. Ramesh, J. Mater Chem. B, 2014, 2, 1432

28. H. P. Erickson, Biol. Proced. Online, 2009, 11, 32.

29. J.J. Babcock and L. Brancaleon, Int. J. Biol. Macromol., 2014, 53, 42-53.

30. H. Zhang, Z. Zhu, Y. Wang, Z. Fei and J. Cao, Appl. Surf. Sci., 2018, 427, 1019-1029.

31. X. Huang, C.S. Brazel and J. Control. Release, 2001, 73, 121-136.

32. H. Hu, C. Tang and C. Yin, Mater. Lett., 2014, 125, 82-85.

33. T. Kumeria, M. Bariana, T. Altalhi, M. Kurkuri, C.T. Gibson, W. Yang and D. Losic, J. Mater. Chem. B, 2013, 45, 6302-6311.

34. X. Zhao, X. Zou and L. Ye, J. Ind. Eng. Chem., 2017, 49, 36-45.

35. X. Ma, H. Tao, K. Yang, L. Feng, L. Cheng, X. Shi, Y. Li, L. Guo and Z. Liu, Nano Res., 2012, 5, 199-212.

36. H. T. Wang, E. Scmitt, D. R. Flanagan and R. J. Linhardt, J. Control. Release, 1991, 17, 23-31.

37. S. R. Sershen, S. L. Westcott, N. J. Halas and J. L. West, J. Biomed. Mater. Res., 2000, 51, 293-298.

38. Y. P. Li, Y. Y. Pei, X. Y. Zhang, Z. H. Gu, Z. H. Zhou, W. F. Yuan, J. J. Zhou and X. J. Gao, J. Control. Release, 2001, 71, 203-211.

39. Z. S. Haidar, R.C. Hamdy and M. Tabrizian, Biomaterials, 2008, 29, $1207-$ 1215.

40. W. E. Hennink, O. Franssen, W. N. E. van Dijk-Wolthuis and H. Talsma, $J$ Control. Release, 1997, 48, 107-114.

41. N. Bhattarai, H. R. Ramay, J. Gunn, F. A. Matsen and M. Zhang, J. Control. Release, 2005, 103, 609-624.

42. H. Kaygusuz and F. B. Erim, React. Funct. Polym., 2013, 73, 1420-1425.

Publisher's Note Engineered Science Publisher remains neutral with regard to jurisdictional claims in published maps and institutional affiliations. 